\title{
Design considerations in the development of a core outcome set
}

\author{
Nicola Harman ${ }^{1 *}$, lain Bruce ${ }^{2}$, Peter Callery ${ }^{3}$, Stephanie Tierney ${ }^{3}$, Kevin O'Brien ${ }^{1}$, Paula Williamson ${ }^{4}$ \\ From 2nd Clinical Trials Methodology Conference: Methodology Matters \\ Edinburgh, UK. 18-19 November 2013
}

No gold standard method currently exists for the development of a core outcome set (COS) although key issues to consider have been identified [1]. Methodological decisions in the design of a project to develop a COS for otitis media with effusion (OME) in children with cleft palate $(\mathrm{CP})$ will be explained.

\section{Stakeholder groups}

Clinicians involved in the management of OME were identified as: ENT surgeons; audiologists; cleft surgeons; speech and language therapists; specialist nurses. Discussions with CLAPA patient groups resulted in a Delphi for patients (7-11, 12-16 years), their parents and adults with $\mathrm{CP}$ and $\mathrm{OME}$.

\section{Separate Delphi panels}

A Delphi exercise has been undertaken with each clinical stakeholder group separately. This method does not assume that different stakeholder groups will have the same outcome priorities.

\section{Describing outcomes for patients and their parents}

A lay description written for each outcome was reviewed by CLAPA groups and reading age assessed. Understanding was tested in a subsample using the think aloud method.

\section{Delivery of the Delphi online}

Each round of the Delphi was delivered online using a bespoke system that managed participation invitations , reminders, data collection and reporting.

The Healing Foundation Cleft and Craniofacial Clinical Research Centre, University of Manchester, Manchester, UK

Full list of author information is available at the end of the article

\section{Integration of clinical and patient views}

Results of the separate Delphi surveys for each stakeholder group will be shared with all participants with an opportunity to re-score. Clinicians, adults, patients and their parents who have taken part in a Delphi panel/ qualitative interview will be invited to a consensus meeting, facilitated by a Study Advisory Group and CLAPA members, to discuss the final COS.

\section{Authors' details}

${ }^{1}$ The Healing Foundation Cleft and Craniofacial Clinical Research Centre, University of Manchester, Manchester, UK. ${ }^{2}$ Central Manchester University Hospitals NHS Foundation Trust, Manchester, UK. ${ }^{3}$ School of Nursing,

Midwifery \& Social Work, University of Manchester, Manchester, UK.

${ }^{4}$ Department of Biostatistics, University of Liverpool, Liverpool, UK.

Published: 29 November 2013

\section{Reference}

1. Williamson PR, Altman DG, Blazeby JM, Clarke M, Devane D, Gargon E, Tugwell P: Developing core outcome sets for clinical trials: issues to consider. Trials 2012, 13:132.

doi:10.1186/1745-6215-14-S1-068

Cite this article as: Harman et al.: Design considerations in the development of a core outcome set. Trials 2013 14(Suppl 1):O68.

Submit your next manuscript to BioMed Central and take full advantage of:

- Convenient online submission

- Thorough peer review

- No space constraints or color figure charges

- Immediate publication on acceptance

- Inclusion in PubMed, CAS, Scopus and Google Scholar

- Research which is freely available for redistribution 